\title{
Increase in antibiotic resistance in Haemophilus influenzae in the United Kingdom since 1977: report of study group
}

\author{
J PHILPOTT-HOWARD, J D WILLIAMS
}

\begin{abstract}
A survey of antibiotic resistance in Haemophilus influenzae was carried out in the United Kingdom with 25 laboratories participating. The incidence of resistance in the 1841 strains examined was: tetracycline $3 \cdot 1 \%$, ampicillin $6.2 \%$, chloramphenicol $1.03 \%$, trimethoprim $1.4 \%$, and sulphamethoxazole $1.5 \%$. Of the 115 strains resistant to ampicillin, 106 produced $\beta$-lactamase. Seventy-nine strains were capsulate, none of which was chloramphenicol resistant, but nine produced $\beta$-lactamase (11.4\%).

Comparison of these figures of antibiotic resistance with those from a similar survey performed in 1977 showed a significant increase in resistance of $\mathbf{H}$ influenzae to ampicillin, chloramphenicol, and trimethoprim.
\end{abstract}

\section{Introduction}

In the past few years several surveys of antibiotic resistance in Haemophilus influenzae have been published ${ }^{1-10}$; of greatest interest are the occurrence of Pittman type b strains resistant to ampicillin $^{6}$ and to chloramphenicol. ${ }^{8}{ }^{10}$ These reports have been of value since the prevalence of resistance influences the

Members of study group: Dr I A Porter, Aberdeen; Dr C A C Ross, Irvine, Ayrshire; Dr A J Howard, Bangor; Dr W D White, Barking; Dr R Wise, Birmingham; Dr D S Reeves, Bristol; Dr X Emmanuel, Edinburgh; Dr M H Robertson, Harlow and Waltham Abbey (Epping); Dr R J Fallon, Glasgow; Dr D A Leigh, High Wycombe; Dr A B White, Inverness; Dr C A Bartzokas, Liverpool; Dr R Gruneberg, London; Professor I Phillips, London; Dr N A Simmons, London; Professor J D Williams, London; Dr R M Stirland, Manchester; Dr J B Selkon, Newcastle; Dr M J Lewis, Nottingham; Dr G M Churcher, Plymouth; Dr O A Okubadejo, Portsmouth; Dr L A Ganguli, Salford; Dr T D Brogan, Stockport; Dr R N Peel, York.

Department of Medical Microbiology, London Hospital Medical College, London E1 2AD

J PHILPOTT-HOWARD, $\mathrm{MB}, \mathrm{BCH}$, lecturer

J D WILLIAMS, MD, MRCPATH, professor choice of antibiotic for treatment of haemophilus disease such as meningitis, respiratory infections, and septic arthritis before the results of sensitivity tests on individual isolates are available.

In 1977, 17 clinical microbiology laboratories in the United Kingdom took part in a study of antibiotic resistance in $H$ influenzae. ${ }^{1}$ Four years later 25 laboratories took part in a second, similar survey, and the results of the two studies were compared.

\section{Methods}

During the three months from February to April 1981 all strains of $H$ influenzae isolated in 25 microbiology laboratories (listed in table II) were sent on chocolate agar slopes to this medical college. One isolate was accepted from each infection episode. On arrival each strain was subcultured on to chocolate agar and examined for purity and viability.

Identification and disc sensitivity testing-Pure cultures of each strain were inoculated into nutrient broth (Oxoid) supplemented with $5 \%$ Fildes' extract (Difco). After incubation at $37^{\circ} \mathrm{C}$ for five hours a one in 100 dilution in peptone water was prepared and the surfaces of the following plates seeded: (i) nutrient agar (Oxoid) for $\mathrm{X}$ and $\mathrm{V}$ factor disc testing, incubated in air at $37^{\circ} \mathrm{C}$ for 18 hours; (ii) Diagnostic Sensitivity Test agar (Oxoid) supplemented with $0.25 \%$ lysed horse blood and $10 \mathrm{mg}$ nicotinamide-adenine dinucleotide (BDH Chemicals Ltd) 1 for susceptibility testing. Filter paper discs, $6 \mathrm{~mm}$ in diameter and containing $10 \mu \mathrm{g}$ tetracycline, $2 \mu \mathrm{g}$ ampicillin, $10 \mu \mathrm{g}$ chloramphenicol, $1.25 \mu \mathrm{g}$ trimethoprim, or $100 \mu \mathrm{g}$ sulphamethoxazole, were applied to the surface. The plate was incubated in an atmosphere of $95^{\circ} \%$ air and $5 \%$ carbon dioxide $\left(\mathrm{CO}_{2}\right)$ at $37^{\circ} \mathrm{C}$ for 18 hours. Organisms that were $\mathrm{X}$ and $\mathrm{V}$ factor dependent, $\mathrm{CO}_{2}$ non-requiring, and nonhaemolytic on horse blood agar were accepted as $H$ influenzae.

Determination of minimum inhibitory concentration-The minimum inhibitory concentrations of the five antibiotics used for disc testing were measured for those strains showing a reduced zone diameter (less than $20 \mathrm{~mm}$ ) to one or more of the antibiotics tested. In addition this concentration was measured for any strain reported by the sending laboratory to be resistant to tetracycline or ampicillin, regardless of the result of disc testing in the college's laboratory. An agar dilution method was used for determining minimum inhibitory concentrations of all antibiotics except sulphamethoxazole. Doubling dilutions of each antibiotic were prepared in Diagnostic Sensitivity Test agar (Oxoid) supplemented with $0 \cdot 25 \%$ lysed horse blood and $10 \mathrm{mg}$ nicotinamide-adenine dinucleotide/l; final concentrations of antibiotic ranged from 0.015 to $128 \mathrm{mg} / \mathrm{l}$. With a Denley multipoint 
TABLE I-Results of disc sensitivity testing compared with minimum inhibitory concentrations of five antibiotics against Haemophilus influenzae

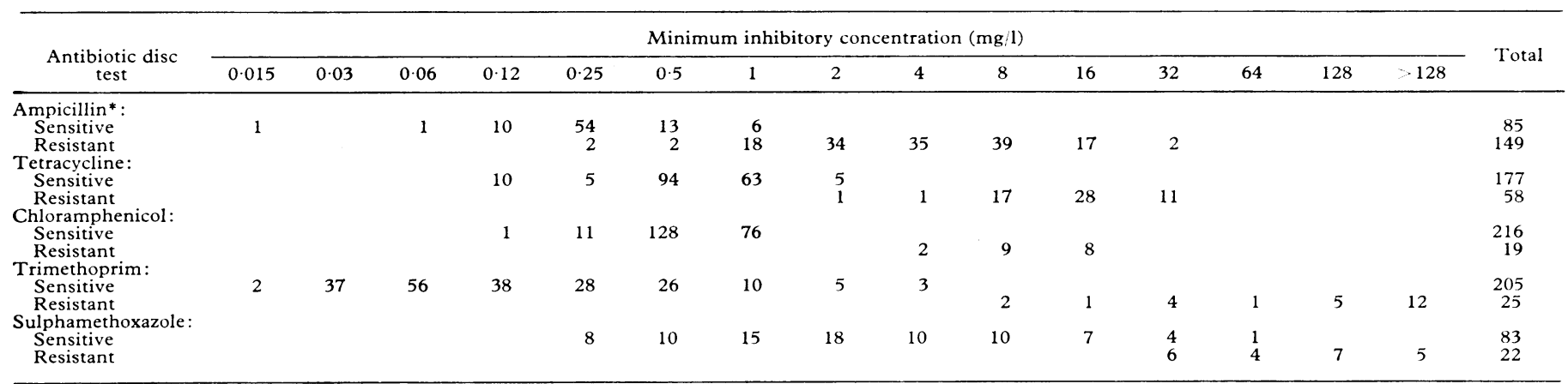

*All strains with a minimum inhibitory concentration of ampicillin of $\geqslant 2 \mathrm{mg} /$ were $\beta$-lactamase positive except for 12 of the strains with a concentration of $2 \mathrm{mg} / \mathrm{l}$, seven with a concentration of $4 \mathrm{mg} / \mathrm{l}$, and two with a concentration of $8 \mathrm{mg} / \mathrm{l}$.

TABLE II-Ampicillin and tetracycline resistance in Haemophilus influenzae

\begin{tabular}{|c|c|c|c|c|c|}
\hline \multirow[b]{2}{*}{ Centre } & \multirow[b]{2}{*}{$\begin{array}{c}\text { No of } \\
\text { isolates } \\
\text { examined }\end{array}$} & \multirow[b]{2}{*}{$\begin{array}{l}\text { No }\left({ }^{\circ} \circ\right) \text { of } \\
\text { isolates } \\
\text { resistant to } \\
\text { tetracycline } \\
(\mathrm{MIC} \\
\geqslant 4 \mathrm{mg} / \mathrm{l})\end{array}$} & \multicolumn{3}{|c|}{ Isolates resistant to ampicillin } \\
\hline & & & $\begin{array}{c}\text { No } \\
\text { B-lactamase } \\
\text { negative } \\
\text { (MIC } \\
\geqslant 4 \mathrm{mg} / \mathrm{l})\end{array}$ & $\begin{array}{c}\text { No } \\
\text { (s-lactamase } \\
\text { positive } \\
\text { (MIC } \\
\geqslant 2 \mathrm{mg} / \mathrm{l})\end{array}$ & $\begin{array}{c}\text { Total } \\
\text { "., }\end{array}$ \\
\hline Aberdeen & 52 & $4(7 \cdot 7)$ & 1 & 4 & $9 \cdot 6$ \\
\hline Ayrshire & 122 & $6(4 \cdot 9)$ & & 9 & $7 \cdot 4$ \\
\hline Bangor & 39 & & & 1 & $2 \cdot 9$ \\
\hline Barking & 74 & $1(1 \cdot 4)$ & 1 & 6 & $9 \cdot 5$ \\
\hline Birmingham & 91 & $4(4 \cdot 4)$ & & 8 & $8 \cdot 8$ \\
\hline Bristol & 47 & $2(4 \cdot 3)$ & & 5 & $10 \cdot 6$ \\
\hline Edinburgh & 88 & $2(87)$ & & 5 & $5 \cdot 7$ \\
\hline Epping & 49 & $2(4 \cdot 1)$ & & 5 & $10 \cdot 2$ \\
\hline Glasgow & 37 & $2(5.4)$ & & 3 & 8.1 \\
\hline High Wycombe & 19 & $1(5 \cdot 3)$ & & 1 & $5 \cdot 3$ \\
\hline $\begin{array}{l}\text { Inverness } \\
\text { Into }\end{array}$ & 73 & $4(5.5)$ & & 2 & $2 \cdot 7$ \\
\hline Liverpool & 58 & & & 2 & $3 \cdot 4$ \\
\hline \multicolumn{6}{|l|}{ London: } \\
\hline Guy's & 49 & & & 4 & $8 \cdot 2$ \\
\hline $\begin{array}{l}\text { London Hospital } \\
\text { Medical College }\end{array}$ & 62 & $2(3 \cdot 2)$ & & 4 & $6 \cdot 5$ \\
\hline St Thomas's & 67 & $4(6.0)$ & & 2 & $\begin{array}{l}0.3 \\
3.0\end{array}$ \\
\hline University College & 41 & $1(2 \cdot 4)$ & & 2 & 4.9 \\
\hline Manchester & 111 & $3(2 \cdot 7)$ & & 1 & $0 \cdot 9$ \\
\hline Newcastle & 180 & $7(3.9)$ & 2 & 13 & $8 \cdot 3$ \\
\hline Nottingham & 204 & $3(1.5)$ & 1 & 12 & $6 \cdot 4$ \\
\hline Plymouth & 204 & $7(3 \cdot 4)$ & 2 & 8 & $4 \cdot 9$ \\
\hline Portsmouth & 52 & $1(1.9)$ & 1 & 5 & $11 \cdot 5$ \\
\hline \multirow{2}{*}{$\begin{array}{l}\text { Salford } \\
\text { Stockport } \\
\text { York }\end{array}$} & 68 & $3(4 \cdot 4)$ & 1 & 3 & 5.9 \\
\hline & $\begin{array}{l}20 \\
34\end{array}$ & & & 1 & $2 \cdot 9$ \\
\hline $\begin{array}{l}\text { Subtotal (") } \\
\text { Total ("0) }\end{array}$ & 1841 & $57(3 \cdot 1)$ & $\begin{array}{l}9(0.5) \\
115\end{array}$ & $(6 \cdot 2)^{106(5 \cdot 8)}$ & \\
\hline
\end{tabular}

MIC $=$ Minimum inhibitory concentration.

inoculator $0.003 \mathrm{ml}$ of a one in 100 dilution of a five-hour broth culture was applied to the surface of the agar. The number of organisms in the inoculum was approximately $10^{4}$. The plates were incubated in an atmosphere of $95 \%$ air and $5 \% \mathrm{CO}_{2}$ for 18 hours. Minimum inhibitory concentrations of sulphamethoxazole were determined by a broth dilution method using Iso-Sensitest broth (Oxoid) supplemented with $0.25 \%$ lysed horse blood and $10 \mathrm{mg}$ nicotinamide-adenine dirucleotide/l. In contrast to agar dilution methods, this produced end-points that could be read without difficulty using an inoculum of $10^{4}$ colony-forming units $/ \mathrm{ml}$.

$\beta$-Lactamase production-All strains for which minimum inhibitory concentrations were determined were tested for $\beta$-lactamase production using the chromogenic cephalosporin G87/312.11

Serotyping-Strains exhibiting iridescence on Fildes' agar were serotyped by a slide agylutination method using agglutinating antiserum obtained from Wellcome Reagents Ltd.

\section{Results}

Of the 2212 strains received, 1841 were suitable for analysis. The strains excluded were those found to be only $\mathrm{X}$ or $\mathrm{V}$ dependent or those that failed to grow on subculture.

Table I shows the minimum inhibitory concentrations of five antibiotics for the strains with reduced inhibition zones to one or more of the antibiotics tested. Reduced zone size correlated fairly precisely with the minimum inhibitory concentration, and the regression analysis will be published elsewhere.

\section{RESISTANCE}

Table II shows the number of strains resistant to tetracycline and ampicillin isolated in each participating laboratory.

Tetracycline-Fifty-seven strains $(3.1 \%$ of all strains tested) showed reduced zone size, requiring $4 \mathrm{mg}$ tetracycline/l for inhibition, and were considered to be resistant. The incidence of resistance to tetracycline in the centres varied from 0 to $7.7 \%$. Eighteen $\left(32^{\circ} \%\right)$ of the tetracycline-resistant organisms were also ampicillin resistant.

Ampicillin-One hundred and forty-nine strains showed a reduced zone of inhibition when iested with the $2 \mu \mathrm{g}$ ampicillin disc. Of these, 22 had a minimum inhibitory concentration of $1 \mathrm{mg}$ ampicillin or less 1 . All 3 -lactamase producers (106 strains) had a minimum inhibitory concentration of $2 \mathrm{mg}$ ampicillin or more/1. Of the strains with reduced zone size but not producing a $\beta$-lactamase, 39 required a minimum $N$ inhibitory concentration of ampicillin of $1 \mathrm{mg}$ or more/l. Of these, nine had a minimum inhibitory concentration of $4 \mathrm{mg}$ or $8 \mathrm{mg} / 1$ and were considered to be resistant. Thirty strains required a minimum inhibitory concentration of 1 or $2 \mathrm{mg} / \mathrm{l}$-an intermediate degree of $\vec{\varphi}$ resistance. Overall, 115 strains $(6 \cdot 2 \%)$ were considered to be ampicillin resistant-that is, 106 3-lactamase producers and nine 3-lactamase non-producers with minimum inhibitory concentrations of ampicillin of $4 \mathrm{mg}$ or more 1 . In addition, 36 strains $\left(2 \cdot 0^{\circ}{ }_{0}\right)$ had an intermediate level of resistance, with minimum inhibitory concentrations of 1 and $2 \mathrm{mg} / \mathrm{l}$ but not producing 3 -lactamase, 30 of which had a reduced zone size (table I).

Chloramphenicol-Nineteen strains $(1.03 \%)$ showed reduced zone size and were found to require a minimum inhibitory concentration of 4 to $16 \mathrm{mg}$ chloramphenicol/1. All were additionally resistant to tetracycline, and six produced $\beta$-lactamase. There were no capsulate strains resistant to chloramphenicol. When the method described by Manten et al ${ }^{12}$ was used each of these resistant strains was shown to produce a chloramphenicol-inactivating enzyme. Six of the 221 isolates from eye infections were chloramphenicol resistant $\left(2 \cdot 7^{\circ}\right)$. This was a higher incidence of chloramphenicol resistance than was found in strains from other sources (13 out of $1620(0.8 \%) ; \chi^{2}=5 \cdot 22$, $\mathrm{p}<0.025)$.

Trimethoprim-Twenty-five strains $\left(1 \cdot 4^{\prime \prime}{ }_{10}\right)$ had a reduced zone size and were inhibited by more than $4 \mathrm{mg}$ trimethoprim/l. Of these, $17 ㅇ$ were also resistant to sulphamethoxazole and six produced $\beta$-lactamase.

Sulphamethoxazole - Twenty-seven strains $\left(1.5^{\circ}\right)$ had reduced of zones of inhibition around the $100 \mu \mathrm{g}$ sulphamethoxazole disc, and $\frac{D}{O}$ all had minimum inhibitory concentrations of $32 \mathrm{mg}$ or more/ 1 by the broth dilution method. In contrast, 78 out of 83 strains with no N reduction in zone size had minimum inhibitory concentrations of 16 N $\mathrm{mg}$ or less/1. Only one resistant strain was capsulate.

\section{SEROTYPES}

Seventy-nine strains $(4.3 \%)$ were capsulate. The following types $\frac{0}{0}$ were identified: Pittman type a, one strain; b, $57(72 \%)$; c, none; d, $\stackrel{\vec{\Phi}}{\mathbb{Q}}$ two; e, 10; and f, nine. Table III compares antibiotic resistance in $\bigcirc$ typable and non-typable strains, including multiply-resistant strains $\stackrel{\mathbb{D}}{\varrho}$ as shown. Ampicillin resistance was more common in type b strains 0 $\left(14 \cdot 0^{\circ}{ }_{0}\right)$ than in non-typable strains $\left(6 \cdot 0^{\circ}{ }_{0}\right)\left(x^{2}=4 \cdot 76, \mathrm{p}<0.05\right)$. No capsulate strains were resistant to chloramphenicol. Five strains of Pittman type $b$ were resistant to trimethoprim, indicating a higher incidence of resistance than in non-capsulate strains $\left(\%^{2}=18 \cdot 46\right.$, $\mathrm{p}<0.0005)$. 
TABLE III-Antibiotic resistance by serotype in Haemophilus influenzae

\begin{tabular}{|c|c|c|c|c|}
\hline & Type b & $\begin{array}{c}\text { Other } \\
\text { serotypes }\end{array}$ & $\underset{\text { Nypable }}{\text { Non- }}$ & $\begin{array}{l}\text { Total } \\
(\%)\end{array}$ \\
\hline No of strains & 57 & 22 & 1762 & \\
\hline $\begin{array}{l}\text { Tetracycline } \\
\text { Ampicillin. }\end{array}$ & 1 & & 56 & $57(3 \cdot 1)$ \\
\hline $\begin{array}{l}\beta \text {-Lactamase positive } \\
\beta \text {-Lactamase negative } \\
\text { Chloramphenicol } \\
\text { Trimethoprim } \\
\text { Sulphamethoxazole }\end{array}$ & $\begin{array}{l}5 \\
1\end{array}$ & 1 & $\begin{array}{r}97 \\
9 \\
19 \\
20 \\
26\end{array}$ & $\begin{array}{l}106(5 \cdot 8) \\
9(0.5) \\
19(1.03) \\
25(1.4) \\
27(1.5)\end{array}$ \\
\hline $\begin{array}{l}\text { Total No of strains resistant } \\
\text { to one or more antibiotics }\end{array}$ & 12 & 1 & 169 & $182(9 \cdot 9)$ \\
\hline
\end{tabular}

\section{Discussion}

Figures for antibiotic resistance in $H$ influenzae in 1977 and 1981 may be compared because, apart from the method used to determine minimum inhibitory concentrations of sulphonamide, identical sensitivity testing methods were performed at the London Hospital Medical College in both surveys. Seventeen microbiology laboratories took part in both the 1977 and 1981 surveys, and only figures from these laboratories were used to determine whether any significant change in antibiotic resistance had occurred during the four-year interval. In addition, eight more laboratories contributed haemophilus isolates to the 1981 survey, and these figures were included for calculation of percentage resistance.

No significant change occurred in tetracycline resistance in the United Kingdom between 1977, when $2.7 \%$ of isolates were resistant to this antibiotic, and 1981, when $3.1 \%$ were resistant.

Resistance to ampicillin increased significantly. In 1977, 1.6\% of 952 isolates were resistant compared with $6.6 \%$ from the same 17 centres in $1981\left(\chi^{2}=32.38, \mathrm{p}<0.0005\right)$. Table IV compares the percentage resistance for each of these centres; all but two showed an increase. The overall resistance in all 25 centres in

\begin{tabular}{|c|c|c|}
\hline Centre & 1977 & 1981 \\
\hline $\begin{array}{l}\text { Aberdeen } \\
\text { Ayrshire } \\
\text { Birmingham } \\
\text { Bristol } \\
\text { Edinburgh } \\
\text { Epping } \\
\text { Glasgow } \\
\text { Guy's } \\
\text { The London } \\
\text { St Thomas's } \\
\text { Liverpool } \\
\text { Nottingham } \\
\text { Plymouth } \\
\text { Portsmouth } \\
\text { Stockport } \\
\text { High Wycombe } \\
\text { York }\end{array}$ & $\begin{array}{l}0 \\
0 \\
0 \\
3 \cdot 8 \\
2 \cdot 8 \\
4 \cdot 3 \\
0 \\
3 \cdot 0 \\
1 \cdot 4 \\
0 \\
0 \\
1 \cdot 1 \\
0 \cdot 7 \\
0 \\
0 \\
13 \cdot 3 \\
0\end{array}$ & $\begin{array}{r}9 \cdot 6 \\
7 \cdot 4 \\
8 \cdot 8 \\
10 \cdot 6 \\
5 \cdot 7 \\
10 \cdot 2 \\
8 \cdot 1 \\
8 \cdot 2 \\
6 \cdot 5 \\
3 \cdot 0 \\
3 \cdot 4 \\
6 \cdot 4 \\
4 \cdot 9 \\
11 \cdot 5 \\
0 \cdot 5 \\
5 \cdot 3 \\
2 \cdot 9\end{array}$ \\
\hline
\end{tabular}

1981 was $6 \cdot 2 \%$. Strains not producing $\beta$-lactamase but requiring 1 or $2 \mathrm{mg}$ ampicillin/l for inhibition were not included as resistant, so that comparison with the 1977 figures could be made. Although most ampicillin-resistant strains could be shown to produce $\beta$-lactamase, nine strains $(0.5 \%$ of the total) were $\beta$-lactamase negative. Such strains are reported to be more prevalent in Australia, ${ }^{13}$ where Bell and Plowman found $2 \%$ of strains to be $\beta$-lactamase negative and yet have minimum inhibitory concentrations of $4 \mathrm{mg}$ or more/l. The mechanism of resistance is unknown. None of the nine strains was capsulate. The $36 \beta$-lactamase negative strains with minimum inhibitory concentrations of 1 or $2 \mathrm{mg}$ ampicillin/l were also non-capsulate.

Ampicillin resistance was significantly more common in type b strains $(14.0 \%)$ than in other serotypes or non-typable strains. This phenomenon was also noted in 1977, when four out of 34 type b strains $(11.8 \%)$ were ampicillin resistant. Because of this, comparisons of the prevalence of ampicillin resistance in different parts of the world must take into account the way in which strains have been selected for sensitivity testing; certain studies give figures for systemic isolates only. In Canada 13\% of 207 type b strains were ampicillin resistant ${ }^{3}$; this compares with a range of $3 \cdot 0-8 \cdot 9 \%$ resistance in systemic isolates from the United States in $1978 .{ }^{\circ}$ In $1979,9.0 \%$ of 46 haemophilus isolates from patients with meningitis in Omaha were resistant. ${ }^{2}$ In Finland ${ }^{5} 12 \cdot 7 \%$ of 102 respiratory isolates were ampicillin resistant, but there was no information on how many of these strains were capsulate. The prevalence of capsulate ampicillinresistant strains is now sufficient to exclude ampicillin as initial treatment of $H$ influenzae meningitis.

Trimethoprim resistance in $1981(1.4 \%)$ was also significantly greater than that in 1977 , when $0.2 \%$ of strains were resistant. Variation between centres was from 0 to $7 \%$. Nevertheless, trimethoprim remains useful, either alone or in combination with sulphamethoxazole, against haemophilus.

Chloramphenicol resistance was also significantly higher in $1981(1.03 \%)$ than in $1977(0.25 \%)$ and was associated with tetracycline resistance. As six of the isolates showing chloramphenicol resistance were also $\beta$-lactamase producers, plasmids coding for resistance to these three antibiotics had probably been acquired, possibly from enterobacteria. ${ }^{14}$ In addition chloramphenicol resistance was more common in isolates from the eye than in strains from other sources. The increase in chloramphenicol resistance could not be accounted for by an increase in eye isolates in 1981 compared with 1977 because the proportion of eye isolates was similar in both surveys. Use of chloramphenicol eye drops has a possible role in selection of these strains. No multiply-resistant capsulate strains have been isolated in the United Kingdom but might be in the future, and this should be anticipated by assessment of new antibiotics suitable for treatment of multiply-resistant haemophilus infections. Agents that might be examined include clavulanic acid with amoxycillin, cefaclor, and other new $\beta$-lactam antibiotics.

We thank Miss Angela Seymour for her technical help during the study.

\section{References}

${ }^{1}$ Howard AJ, Hince CJ, Williams JD. Antibiotic resistance in Streptococcus pneumoniae and Haemophilus influenzae. $\mathrm{Br}$ Med $\mathcal{F}$ 1978;i:1657-60.

2 Lerman SJ, Brunken JM, Bollinger M. Prevalence of ampicillin-resistant strains of Haemophilus infl denzae causing systemic infection. Antimicrob Agents Chemother 1980;18:474-5.

${ }^{3}$ Scheifele DW. Ampicillin-resistant Haemophilus influenzae in Canada: nationwide survey of hospital laboratories. Can Med Assoc $\mathcal{f}$ 1979;121: 198-202.

4 Saginur R, Bartlett JG. Antimicrobial drug susceptibility isolates of Haemophilus influenzae from adults. Am Rev Respir Dis 1981;122:61-4.

5 Jokipii L, Jokipii AMM. Emergence and prevalence of beta-lactamaseproducing Haemophilus influenzae in Finland and s dsceptibility of 102 respiratory isolates to eight antibiotics. F Antimicrob Chemother 1980; 6:623-31.

6 Thomas WJ, McReynolds JW, Mock CR, Bailey DW. Ampicillinresistant Haemophilus influenzae meningitis. Lancet 1974 ;i:313.

${ }^{7}$ Khan W, Ross S, Rodriguez W, Controni G, Saz AK. Haemophilus influenzae type $\mathrm{b}$ resistant to ampicillin. $\mathcal{F} A M A$ 1974;229:298-301.

${ }^{8} \mathrm{Kinmonth} A \mathrm{~L}$, Storrs CN, Mitchell RG. Meningitis due to chloramphenicol-resistant Haemophilus influenzae type b. Br Med $\mathcal{F}$ 1978;i:694.

9 Ward JI, Tsai TF, Filice GA, Drasar DW. Prevalence of ampicillin- and chloramphenicol-resistant strains of Haemophilus influenzae causing meningitis and bacteraemia: national survey of hospital laboratories. f Infect Dis 1978;138:421-4.

10 Simasathien S, Duangmani C, Echeverria P. Haemophilus influenzae type $b$ resistant to ampicillin and chloramphenicol in an orphanage in Thailand. Lancet 1980;ii:1214-7.

11 O'Callaghan CH, Morris A, Kirby SM. Novel method for the detection of beta-lactamases using a chromogenic cephalosporin substrate. Antimicrob Agents Chemother 1972;1:283-8.

12 Manten A, van Klingeren B, Dessens-Kroon M. Chloramphenicol resistance in Haemophilus influenzae. Lancet 1976; : 702.

13 Bell SM, Plowman D. Mechanisms of ampicillin resistance in Haemophilus influenzae from respiratory tract. Lancet $1980 ; \mathrm{i}: 279-80$.

14 Rotimi VO, Turk DC. Transferable multiple antibiotic resistance in Haemophilus influenzae. $f$ Antimicrob Chemother $1981 ; 8: 187-92$.

(Accepted 2 April 1982) 